\title{
Flow Boiling of HFE-7100 in Multi-Microchannels: Effect of Surface Material
}

\author{
Ali H. Al-Zaidi' ${ }^{\text {, Mohamed M. Mahmoud }}{ }^{2}$, Tassos G. Karayiannis ${ }^{3}$ \\ ${ }^{1}$ University of Misan, Al-Amarah, Iraq \\ alialzaidi@uomisan.edu.iq; mbasuny@zu.edu.eg \\ ${ }^{2}$ Faculty of Engineering, Zagazig University, Zagazig, Egypt, 44519; \\ mbasuny@zu.edu.eg \\ ${ }^{3}$ Department of Mechanical and Aerospace Engineering, Brunel University London, UK \\ tassos.karayiannis@brunel.ac.uk
}

\begin{abstract}
The effect of surface material on the flow boiling characteristics in a multi-microchannel evaporator is described in this paper. HFE-7100, a dielectric and eco-friendly working fluid, was tested at atmospheric pressure, inlet sub-cooling of $5 \mathrm{~K}$, base heat flux up to $433.5 \mathrm{~kW} / \mathrm{m}^{2}$ and mass flux range $50-250 \mathrm{~kg} / \mathrm{m}^{2} \mathrm{~s}$. Two heat sinks made of copper and aluminium were fabricated having the same channel dimensions giving a hydraulic diameter of $0.46 \mathrm{~mm}$ with a base area of $500 \mathrm{~mm}^{2}$. The average roughness was measured and the values were $0.286 \mu \mathrm{m}$ and $0.192 \mu \mathrm{m}$ for the copper and aluminium, respectively. The effect of surface material was not significant at low heat flux. However, it became significant at moderate and high wall heat fluxes. The flow patterns for the two microchannels were similar and included bubble, slug, churn and annular flow. The experimental results showed that the aluminium surface achieved on the average difference of $12 \%$ higher heat transfer coefficients than those found in the copper microchannel. It also gave higher flow boiling pressure drop; the average difference was up-to approximately $30 \%$. The different surface microstructures in the two examined heat sinks could explain the different heat transfer and pressure drop behaviour.
\end{abstract}

Keywords: Flow boiling pressure drop, Heat transfer coefficient, Microchannels, Material effect, Electronics cooling.

\section{Introduction}

The growing demand for an effective cooling system for different electronic devices encouraged researchers to propose and test different cooling techniques. Two-phase flow boiling in a pumped loop system is one of the promising cooling techniques that could be used in different applications, such as microprocessors, Insulated Gate Bipolar Transistors (IGBT) and fuel cell stacks. It has several advantages: high heat transfer coefficient, uniform substrate surface temperature and the possible low pumping power for a given load. However, there are many challenges in using the two-phase flow boiling in micro passages for cooling high heat flux systems, including the lack of general definition of micro scale and disagreement about the dominant heat transfer mechanism(s), the high wall superheat at boiling incipience, the lack of general prediction correlations for flow patterns, pressure drop and heat transfer coefficient, system instabilities, flow reversal and clear understanding of the effect of surface characteristics/geometry [1]. Accordingly, further investigations are still required to clarify the effect of the flow and geometrical parameters. The influence of surface material is an important parameter that may affect the heat transfer behaviour. This parameter was examined during this study.

\section{Experimental Setup and Data Reduction}

The experimental facility was described in detail in [2] and it consisted of liquid reservoir, sub-cooler, micro-gear pump, Coriolis flow meters, pre-heater, test section, Phantom high-speed camera and chiller system as shown in Fig. 1. The test section consisted of four parts namely cover plate, housing, bottom plate and heat sink block as illustrated in Fig. 2 . The cover plate was made of a transparent polycarbonate sheet to allow flow visualization, while both the housing and the bottom plate were made of Polytetrafluoroethylene to ensure low heat loss. Two heat sinks made of oxygen-free copper and aluminium were manufactured using high-precision milling machine (Kern HSPC-2216). The same cutting speed and tool were used. Each heat sink consisted of 36 microchannels having channel height of $0.46 \mathrm{~mm}$, channel width of $0.46 \mathrm{~mm}$ and a separating fin width of $0.1 \mathrm{~mm}$. The channel hydraulic diameter, aspect ratio, heated length and base width were $0.46 \mathrm{~mm}$, $1,25 \mathrm{~mm}$ and $20 \mathrm{~mm}$, respectively. 


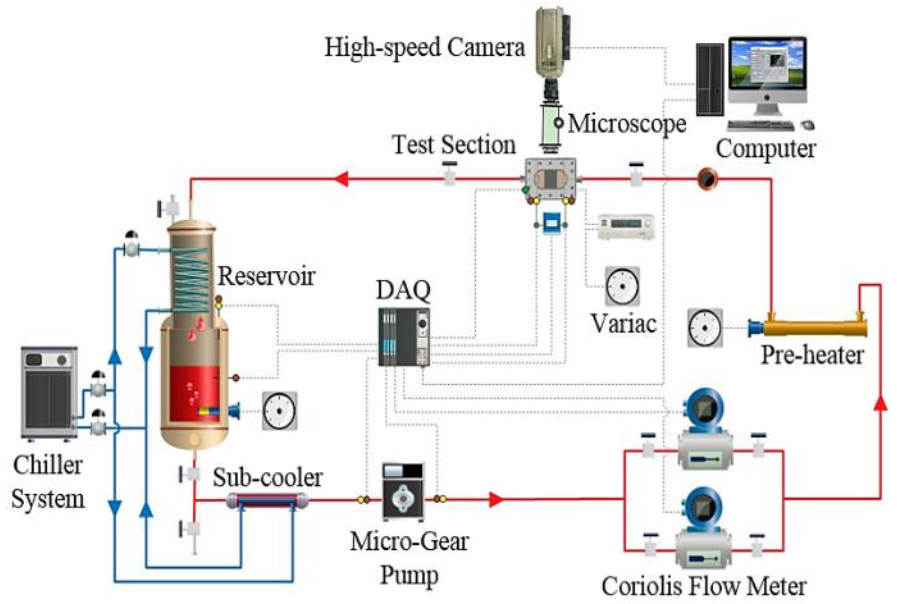

Fig. 1: Schematic diagram of the experimental rig [2].

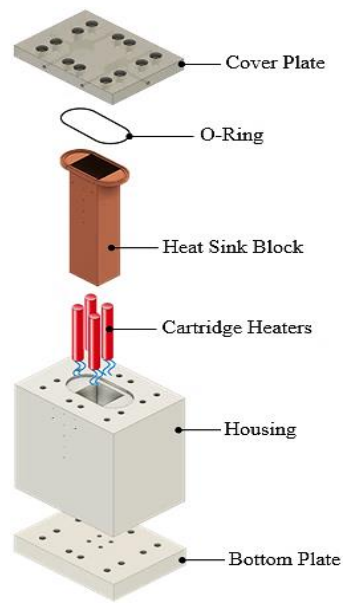

Fig. 2: Exploded drawing of the test section [2].

A surface profiler instrument using Zygo NewView 5000 was used to measure the average surface roughness of the channel bottom at different locations and then the average value was taken. The average surface roughness of both copper and aluminium surfaces were found to be $0.286 \mu \mathrm{m}$ and $0.192 \mu \mathrm{m}$, respectively. Because the cutting speed and cutting feed rate were exactly the same, the difference in the average surface roughness could be due to the material properties. Four cartridge heaters with total power of $700 \mathrm{~W}$ were inserted vertically from the bottom of the heat sink. Two pressure transducers, one differential pressure transducer and fourteen thermocouples were inserted inside the test section. The measured data were saved for two minutes and then averaged, after steady state was reached. Steady state was confirmed when all the measured signals are stable with time. The local heat transfer coefficient was calculated at three locations using Eq. (1).

$$
h_{(z)}=\frac{q_{b}^{\prime \prime}\left(W_{c h}+W_{f i n}\right)}{\left(T_{w i(z)}-T_{f(z)}\right) *\left(W_{c h}+2 \eta * H_{c h}\right)}
$$

where $q^{\prime \prime}{ }_{b}, H_{c h}, W_{c h}, W_{f i n}, T_{w i(z)}, T_{f(z)}$ and $\eta$ are the base heat flux, the channel height, the channel width, the fin width, the local internal (base) wall temperature, the local fluid temperature and the fin efficiency, respectively. The local fluid temperature was equal to the local liquid temperature (in single-phase region) or the local saturation temperature (in twophase region). The local saturation temperature was found corresponding to the local pressure by assuming linear pressure drop along the channels. The base heat flux $q^{\prime \prime}{ }_{b}$ was calculated from the vertical temperature gradient, see [2] for further details. $T_{w i(z)}$ was obtained from the local thermocouple reading, adjusted to account for the distance from the bottom wall surface, [2]. The two-phase pressure drop $\Delta P_{t p}$ was calculated by subtracting the channel pressure drop $\Delta P_{c h}$ from the singlephase pressure drop $\Delta P_{s p}$ as follows:

$$
\Delta P_{t p}=\Delta P_{c h}-\Delta P_{s p}
$$

The uncertainty calculations for the measured and derived variables were calculated using the procedure described by [3]. A Scanning Electron Microscope analysis was carried out for these heat sinks to record the different surface microstructures. Fig. 3 shows the surface topography of both copper and aluminium at magnification of 2000X using LEO 1455VP microscope. This figure indicates that the surface topography of copper was completely different from the aluminium surface. The copper surface showed smoother surface topography and less cutting marks (peaks). This surface also had less surface cavities and smaller size compared to aluminium. Different cutting marks could result in different surface peaks and valleys. All these surface microstructures and especially the number and size of cavities can have a significant influence on the heat transfer behaviour especially in micro passages. The channels were cleaned by pressurised nitrogen before use. As seen in the photograph, the 
aluminium surface had more debris than copper; these small particles were not removed by the pressurised nitrogen. However, their effect on the flow and heat transfer is negligible compared to the effect of the cavity size/distribution and the peaks and valleys resulting from the machining process.

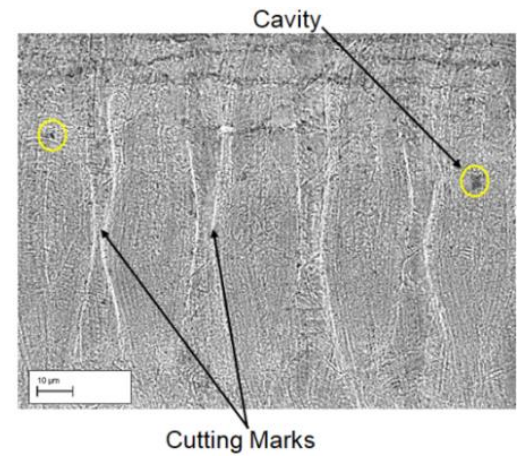

a)

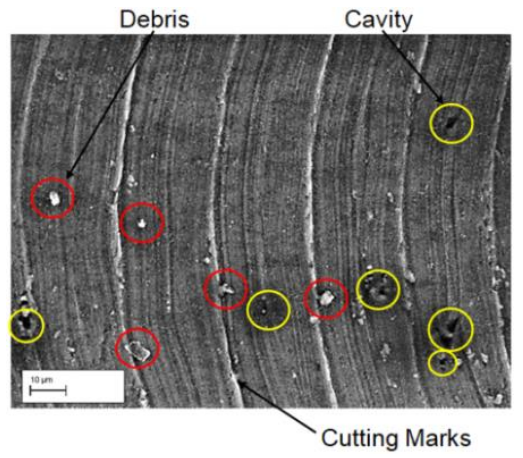

b)

Fig. 3: Topography images from SEM at magnification of 2000X: (a) copper (b) aluminium.

\section{Experimental Results and Discussion}

\section{1. Heat transfer characteristics}

Fig. 4 depicts the influence of surface material on the local heat transfer coefficient at mass flux of $250 \mathrm{~kg} / \mathrm{m}^{2} \mathrm{~s}$ for low and high wall heat fluxes. It shows that high local heat transfer coefficient was found at very low vapour qualities and then decreased with increasing quality. This reduction at low vapour quality could be due to the boiling incipience giving high values and the subsequent transition from bubbly to slug flow regime. The decreasing trend in the high-quality region could be due to instantaneous dry out occurring in few channels arising from the flow maldistribution, which is very common in multimicrochannels. This could increase the average surface temperature along the channel.

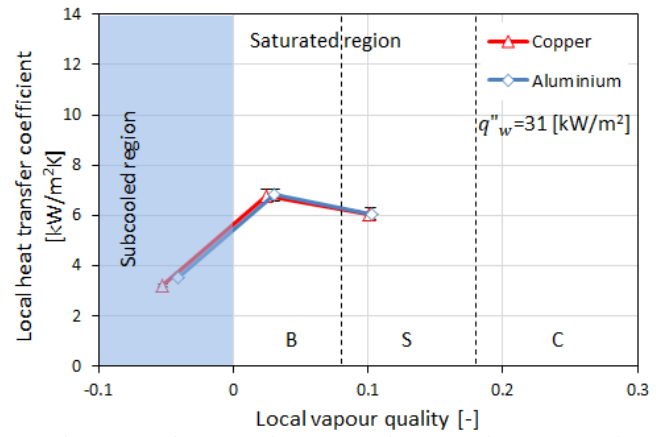

a)

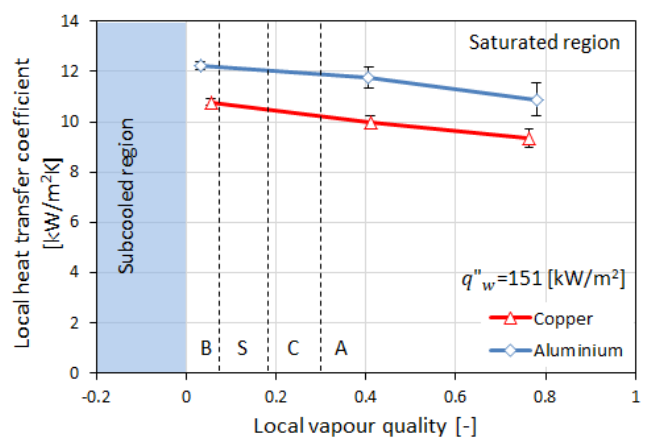

b)

Fig. 4: Effect of surface material on the local heat transfer coefficient at mass flux of $250 \mathrm{~kg} / \mathrm{m}^{2} \mathrm{~s}$ :

(a) low heat flux (b) high heat flux. B (bubbly), S (slug), C (churn) and A (annular). 


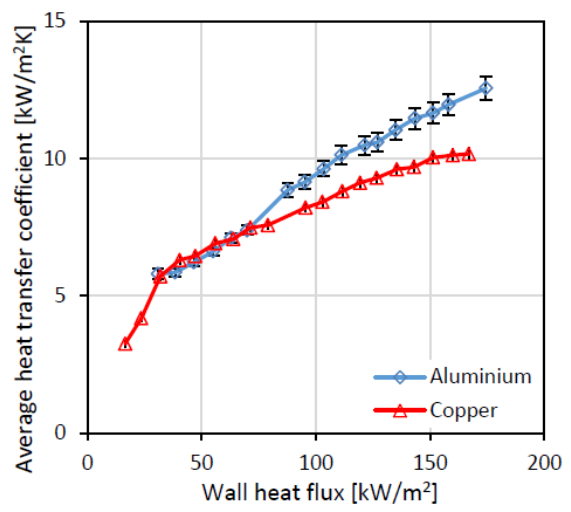

Fig. 5: Effect of surface material on the average heat transfer coefficient at mass flux of $250 \mathrm{~kg} / \mathrm{m}^{2} \mathrm{~s}$.

Fig. 4 also illustrates that, at low wall heat flux, i.e. $31 \mathrm{~kW} / \mathrm{m}^{2}$, there was no material effect. In contrast, at high wall heat flux, i.e. $151 \mathrm{~kW} / \mathrm{m}^{2}$, the aluminium microchannel provided higher local heat transfer coefficient compared to the copper microchannel. Fig. 5 depicts the effect of material on the average heat transfer coefficient for the heat flux range studied at mass flux of $250 \mathrm{~kg} / \mathrm{m}^{2} \mathrm{~s}$. The effect and magnitude of change was similar for the entire mass flux range. As mentioned above, the aluminum surface had more surface cavities and peaks and valleys than copper. This may lead to more nucleation sites on the aluminium compared to copper as the heat flux increased and hence enhanced the heat transfer rates. Additionally the pronounced peaks-valleys on the aluminium surface may disturb the liquid film leading to thinner thickness.

\section{2. Pressure drop characteristics}

The effect of surface material on the flow boiling pressure drop at mass flux of $100 \mathrm{~kg} / \mathrm{m}^{2} \mathrm{~s}$ and $250 \mathrm{~kg} / \mathrm{m}^{2} \mathrm{~s}$ is illustrated in Fig. 6. This figure demonstrates that the flow boiling pressure drop increased with increasing wall heat flux for both materials. This could be due to the high bubble generation and thus high coalescence rate between these bubbles that led to increase the flow resistance and hence the pressure drop inside the channels. This figure also shows that aluminium surface provided higher pressure drop than copper. This became significant at moderate and high heat fluxes. Different surface microstructures may result in different nucleation characteristics which may increase the pressure drop. Pike-Wilson [4] investigated flow boiling of R245fa in vertical metallic tubes made of copper, brass and stainless steel and stated that surface structure may define the size and number of nucleation sites that could affect the pressure drop.
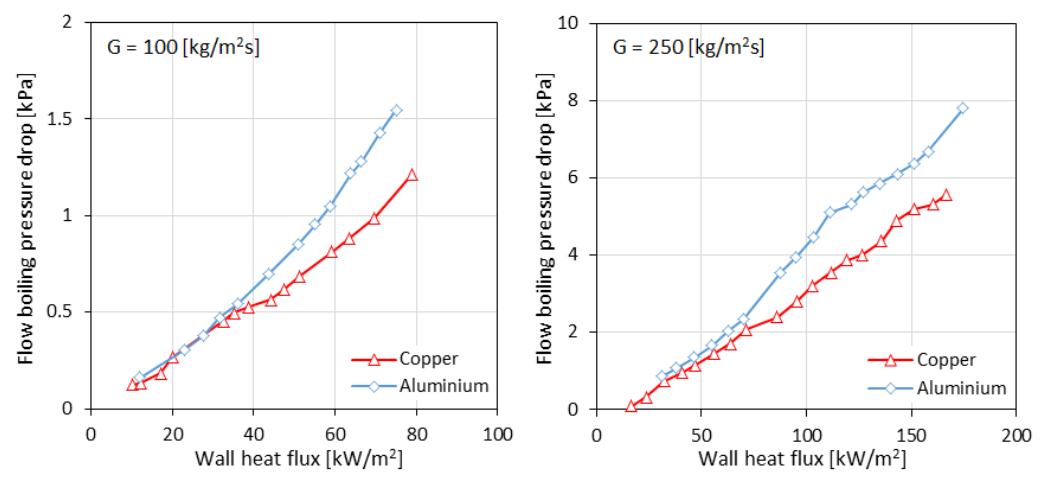

Fig. 6: Effect of surface material on the flow boiling pressure drop at mass flux of: (a) $100 \mathrm{~kg} / \mathrm{m}^{2} \mathrm{~s}$ (b) $250 \mathrm{~kg} / \mathrm{m}^{2} \mathrm{~s}$.

\section{Conclusions}

Flow boiling of HFE-7100 in multi-microchannel heat sink made of copper and aluminium was investigated during the present study. The main conclusions can be summarized as follows: 
1. The flow patterns observed were bubble, slug, churn and annular flow.

2. The local heat transfer coefficient reached higher value at very low qualities, and then decreased with increasing local vapour quality.

3. The effect of surface material on the heat transfer coefficient was not significant at low heat fluxes (less than 60 $\mathrm{kW} / \mathrm{m}^{2}$ ). The effect was more obvious at higher heat flux values with the aluminium surface giving on average $12 \%$ higher heat transfer coefficient than the copper surface. The greater number of cavities found in the aluminium surface as well as the more significant peaks created by the machining process are probably the main reason for this increase.

4. Flow boiling pressure drop was found to increase with increasing heat flux due to the high flow resistance.

5. The aluminium surface showed higher flow boiling pressure drop than that in copper. This became significant at moderate and high wall heat fluxes and can be attributed to surface characteristics as mentioned above.

\section{Acknowledgements}

Ali Al-Zaidi would like to thank the Iraqi Ministry of Higher Education and Scientific Research for their financial support.

\section{References}

[1] T. G. Karayiannis and M. M. Mahmoud, "Flow boiling in microchannels: Fundamentals and applications," Appl. Therm. Eng., vol. 115, pp. 1372-1397, 2017.

[2] A. H. Al-Zaidi, M. M. Mahmoud and T. G. Karayiannis, "Flow boiling of HFE-7100 in microchannels: Experimental study and comparison with correlations," Int. J. Heat Mass Transf., vol. 140, pp. 100-128, 2019.

[3] H. W. Coleman and W. G. Steele, Experimentation and uncertainty analysis for engineers, 3nd. New York: Wiley, Chichester, 2009.

[4] E. A. Pike-Wilson and T. G. Karayiannis, "Flow boiling of R245fa in $1.1 \mathrm{~mm}$ diameter stainless steel, brass and copper tubes," Exp. Therm. Fluid Sci., vol. 59, pp. 166-183, 2014. 